\title{
Case Series: Gamma Knife as Salvage Therapy for Recurrent Glioblastoma Multiforme
}

Erik W Larson ${ }^{1,2,3}$, Halloran E Peterson ${ }^{1,2,3}$, Wayne T Lamoreaux ${ }^{1,2}$, Alexander R MacKay ${ }^{1}$, Robert K Fairbanks ${ }^{1,2}$, Jason A Call ${ }^{2}$, Jonathan D Carlson ${ }^{1,4}$, Benjamin C Ling ${ }^{4}$, John J Demakas ${ }^{1,5}$, Barton S Cooke ${ }^{1}$, Ben Peressini ${ }^{6}$ and Christopher M Lee ${ }^{1,2^{*}}$

${ }^{1}$ Gamma Knife of Spokane, 910 W 5th Ave, Suite 102, Spokane, WA 99204, USA

${ }^{2}$ Cancer Care Northwest, 910 W 5th Ave, Suite 102, Spokane, WA 99204, USA

${ }^{3}$ University of Washington School of Medicine, 1959 NE Pacific St, Seattle, WA 98195, USA

${ }^{4}$ Inland Neurosurgery and Spine Associates, 105 W 8th Ave, Suite 200, Spokane, WA 99204, USA

${ }^{5}$ Spokane Brain and Spine, 801 W 5th Ave, Suite 210, Spokane, WA 99204, USA

${ }^{6}$ DataWorks Northwest, LLC, 3952 N Magnuson St, Coeur D'Alene, ID 83815, USA

*Corresponding author: Christopher M. Lee, MD, Gamma Knife of Spokane and Cancer Care Northwest, 910 W 5th Ave., Suite 102, Spokane, WA 99204, USA, Tel: 509 228-1000; Fax: 509 228-1183; E-mail: lee@ccnw.net

Rec date: Aug 24, 2014, Acc date: Sep 11, 2014, Pub date: Sep 22, 2014

Copyright: ( 2014 Larson EW, et al. This is an open-access article distributed under the terms of the Creative Commons Attribution License, which permits unrestricted use, distribution, and reproduction in any medium, provided the original author and source are credited.

\begin{abstract}
Objectives: Glioblastoma multiforme is a highly malignant primary tumor of the brain. It has a dismal survival prognosis of 14-16 months following initial diagnosis. Despite aggressive upfront therapy, glioblastoma tends to recur in twelve months. Following this recurrence, some patients may benefit from Gamma Knife Radiosurgery (GKRS) treatment. This study analyzes survival outcomes in a case series by studying known prognostic indicators for glioblastoma patients.

Methods: 63 patients with recurrent glioblastoma were treated with GKRS as part of a multimodal treatment plan between 2002 and 2011. Overall survival (from date of diagnosis) was compared to expected survival times as indicated by updated RTOG recursive partitioning analysis (RTOG-RPA) Classes. Survival post-GKRS salvage was also investigated. Univariate and multivariate analyses were conducted to determine whether there were significant predictors of overall survival for patients undergoing GKRS salvage.
\end{abstract}

Results: Overall median survival from time of initial diagnosis was $20.2 \pm 2.7$ months for the entire group. 46 patients were in RTOG-RPA Class IV with a median overall survival of $20.2 \pm 2.6$ months (expected prognosis: 11.2 months). Median survival following GKRS salvage therapy was $9.9 \pm 3.1$ months for all patients. Multivariate analysis indicated that KPS was a significant predictor of survival (Hazard Ratio 0.22 compared to a KPS of 80).

Conclusions: GKRS may be a safe and effective salvage therapy for selected recurrent glioblastoma patients, providing prolonged survival and quality of life compared to patients not receiving salvage treatment. Treatment options should be appropriately tailored to each patient's individual situation.

Keywords: Gamma knife; Radiosurgery; Recurrent glioblastoma

\section{Introduction}

Glioblastoma multiforme (GBM) is the most common malignant primary brain tumor in adults with an incidence of 3.005 per 100,000 in the United States [1] and is almost always uniformly fatal [2]. Classically, the best available therapeutic approach for most patients consists of gross total resection, temozolomide chemotherapy, and external beam radiation therapy (EBRT) [3-8]. Despite this regimen, these patients typically experience recurrence of GBM 6 months later with an overall total survival of 14-16 months. Stereotactic radiosurgery has not shown to provide a survival benefit when administered as upfront treatment in combination with EBRT, for newly diagnosed GBM $[4,9]$. Factors which historically predict a more favorable prognosis for GBM patients are age less than 50, Karnofsky Performance Status (KPS) of 90 or better, and achieving gross total resection [10-14]. Additional studies have shown an improved prognosis for smaller volume tumors $(<15 \mathrm{cc})$, unifocal lesions, use of additional salvage therapies, and O6-methylguanine-DNA methyltransferase (MGMT) promoter methylation, and Asian/Pacific Islander ethnicity [15-19].

Despite aggressive upfront therapy for newly diagnosed GBM, these tumors tend to recur within six months. This is due to the resistance of tumor cells to radiation and chemotherapy and the microscopic, infiltrative growth of tumor cells along white matter tracts up to $4 \mathrm{~cm}$ away from the original gross tumor location [20]. Treatment options for recurrent GBM (rGBM) are an area of interest. Primarily the aim of these treatments is to extend overall survival and improve quality of life. Some studies have focused on chemotherapeutic salvage options $[5,13,21-23]$, but this relies on a patient's ability to tolerate repeat chemotherapy side effects [24]. Salvage surgical treatment, while effective in select cases[18,25,26], may not be an option for patients suffering from extensive tumors, or those affecting eloquent areas. Recovery from surgery may also be too challenging for a patient and their family during the terminal state of this illness. Repeated 
Page 2 of 7

conformal radiation therapy presents a high risk of radionecrosis or radiation-induced edema without providing substantial benefit $[27,28]$. Stereotactic radiosurgery therapies, such as Gamma Knife radiosurgery (GKRS), have the ability to deliver a high dose of radiation to a focal region while limiting the dose to surrounding healthy tissue, in many respects similar to the targeted second surgical resection of a GBM. Stereotactic radiosurgery has also shown to provide a survival benefit for those in which repeat surgical resection is not indicated [29]. Multiple studies have offered evidence to support a survival benefit for select rGBM patients who receive GKRS salvage treatment $[15,16,18,30-35]$.

We present the results of 63 patients suffering from recurrence of histopathologically confirmed GBM who received between 1 and 5 salvage GKRS treatments at a single institution. The aim of this study was to retrospectively analyze survival outcomes relative to known clinical prognostic indicators.

\section{Materials and Methods}

We examined the records 63 patients with a diagnosis of GBM between 2002 and 2011 who underwent GKRS salvage therapy. No patients were excluded. All patients were treated at Gamma Knife of Spokane using the Model C Leksell 60Co Gamma Knife (Elekta, Stockholm, Sweden). Prior to the GKRS procedure, local anesthetic was applied to facilitate placement of the stereotactic head frame. Gadolinium enhanced magnetic resonance imaging of the head within the coordinate frame was performed and then a neurological surgeon, radiation oncologist, and medical physicist concurrently planned the radiosurgery treatment. 47 patients received only one GKRS salvage treatment and 16 patients had two or more treatments. 13 patients had salvage resections, and 2 patients received bevacizumab salvage chemotherapy.

The patients were grouped by resection extent (biopsy, subtotal, or gross total as determined by postoperative MRI), by age at glioblastoma diagnosis $(<50 \mathrm{y}, \geq 50 \mathrm{y})$, by KPS value $(60,70,80,90,100$, unknown), Gamma Knife treatment dose (<14Gy, 14-15Gy, 16Gy, >16 $\mathrm{Gy})$, and by tumor volume $(<15 \mathrm{cc}, \geq 15 \mathrm{cc})$. Table 1 shows number of patients in number of patients in these different defined groups.

\begin{tabular}{|l|l|l|l|l|}
\hline Characteristic & Biopsy & Subtotal & GT & Total \\
\hline & $\mathbf{n = 1 0}$ & $\mathbf{n = 2 6}$ & $\mathbf{n = 2 7}$ & $\mathbf{n = 6 3}$ \\
\hline $\begin{array}{l}\text { Age at diagnosis, } \\
\text { median (range) }\end{array}$ & $53(28-85)$ & $57(28-85)$ & $52(23-76)$ & $55(23-85)$ \\
\hline$<50$ & 3 & 10 & 6 & 19 \\
\hline$>=50$ & 7 & 17 & 20 & 44 \\
\hline KPS & 1 & 0 & 2 & 3 \\
\hline 60 & 2 & 9 & 5 & 16 \\
\hline 70 & 4 & 5 & 8 & 17 \\
\hline 80 & & & & \\
\hline
\end{tabular}

\begin{tabular}{|l|l|l|l|l|}
\hline 90 & 2 & 3 & 7 & 12 \\
\hline 100 & 0 & 8 & 4 & 12 \\
\hline Unknown & 1 & 1 & 1 & 3 \\
\hline GK Dose (Gy) & & & 5 & \\
\hline$<14$ & 5 & 4 & 5 & 14 \\
\hline $14-15$ & 3 & 6 & 6 & 15 \\
\hline 16 & 2 & 14 & 13 & 29 \\
\hline$>16$ & 0 & 2 & 3 & 5 \\
\hline Tumor volume (cc) & & 14 & 8 & 28 \\
\hline$<15$ & 3 & 7 & 16 & 9 \\
\hline$\geq 15$ & 6 & 5 & 3 & $26.0-63.6)$ \\
\hline $\begin{array}{l}\text { Unknown } \\
\text { median (range) }\end{array}$ & 1 & & & \\
\hline
\end{tabular}

Table 1: Patient population baseline characteristics, GT: Gross Total resection, KPS: Karnofsky Performance Status, GK: Gamma Knife

Survival curves were estimated using the Kaplan-Meier method and used to compare resection extent groups, KPS groups, Gamma Knife treatment dose groups, and tumor volume groups. Andersen $95 \%$ confidence intervals for the median survival time of the groups were constructed [36]. Log-rank tests were employed to determine if there is statistical evidence of differences between the survival curves of the groups. Finally, the Cox proportional hazard model was used in a multivariate analysis of the resection extent groups, age groups, KPS groups, Gamma Knife treatment dose groups, and tumor volume groups. All statistical analyses utilized StatsDirect Version 2.7.3 (StatsDirect Ltd., Altrincham, UK) and SigmaPlot Version 12.3 (SYSTAT Software, Inc., San Jose, CA).

\section{Results}

The median survival of this cohort of patients was 20.2 months ( \pm 2.7 months) (Figure 1). This is better than the average survival predicted by historical studies using the conventional treatment regimen particularly for RTOG-RPA Class IV as shown in Table 2.

This may be in part due to GKRS salvage. Following GKRS salvage therapy, median survival was 9.9 months $( \pm 3.1$ months) (Figure 2). There were no statistically significant differences in the Kaplan-Meier survival curves for resection extent groups, comparing biopsy, partial, and gross total resection (Figure 3). Patients with higher KPS scores tended to have longer survival (Figure 4).

There was no report of any complications or adverse radiation events due to GKRS for any patient in this study.

\begin{tabular}{|l|l|l|l|l|l|}
\hline $\begin{array}{l}\text { RTOG-RPA } \\
\text { Class }\end{array}$ & Defining Variables & Li, et al. 2011 & Present Study & \# of patients & $\mathbf{9 5 \%} \mathrm{Cl}$ \\
\hline III & age $<50$ y and KPS $\geq 90$. & 17.1 & 17.3 & 6 & Not Significant \\
\hline
\end{tabular}


Citation: Larson EW, Peterson HE, Lamoreaux WT, MacKay AR, Fairbanks RK, et al. (2014) Case Series: Gamma Knife as Salvage Therapy for

Page 3 of 7

\begin{tabular}{|l|l|l|l|l|l|}
\hline IV & $\begin{array}{l}\text { age }<50 \mathrm{y} \text { and } \mathrm{KPS}<90 ; \\
\text { age } \geq 50 \mathrm{y}, \mathrm{KPS} \geq 70, \text { resection, and working. }\end{array}$ & 11.2 & 20.2 & 46 & $17.6-22.8$ \\
\hline $\mathrm{V}$ & $\begin{array}{l}\text { age } \geq 50 \mathrm{y}, \mathrm{KPS} \geq 70, \text { resection, and not working; } \\
\text { age } \geq 50 \mathrm{y}, \mathrm{KPS} \geq 70, \text { biopsy only; } \\
\text { age } \geq 50 \mathrm{y}, \mathrm{KPS}<70 .\end{array}$ & 7.5 & 11 & 8 & $6.6-15.4$ \\
\hline
\end{tabular}

Table 2: Comparison of overall survival from diagnosis rates in updated RTOG-RPA Classes (months), RTOG-RPA: Radiation Therapy Oncology Group Recursive Partitioning Analysis, KPS: Karnofsky Performance Status

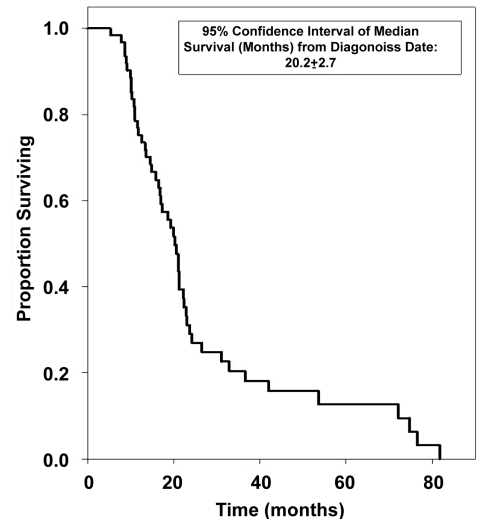

Figure 1: Overall survival from original diagnosis date

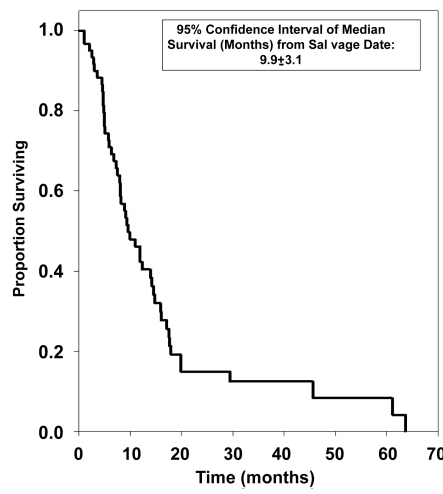

Figure 2: Survival from date of first Gamma Knife salvage therapy for recurrent disease

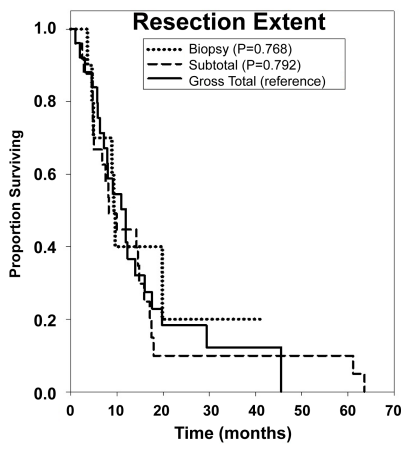

Figure 3: Overall survival curves based on extent of resection

Univariate median survival confidence interval and hazard ratio confidence intervals are included in Table 3 . Within each category a reference group was selected (resection $=\mathrm{GT}$, age $<50 \mathrm{y}, \mathrm{KPS}=80$, dose $=16 \mathrm{~Gy}$, tumor volume $<15 \mathrm{cc}$ ) against which the other groups' hazard ratios were tested.

The hazard ratio of the GT resection group was not found to be statistically different than the others. The hazard ratio of the $\geq 50$ age group was not statistically different than the $<50$ reference group $(\mathrm{P}=0.221)$. Both the KPS $=60$ and KPS $=100$ groups had hazard ratios different than the reference group of $\mathrm{KPS}=80(\mathrm{P}=0.021$ and $\mathrm{P}=0.034$, respectively).

The analyses of the gamma knife treatment dose groups did not yield any statistically significant results. With respect to tumor volume, the $\geq 15$ cc group's hazard ratio was determined to be statistically different from the $<15 \mathrm{cc}$ reference group $(\mathrm{P}=0.019)$.

\begin{tabular}{|c|c|c|c|c|c|}
\hline & \multicolumn{2}{|c|}{ Median Survival } & \multicolumn{3}{|c|}{ Hazard Ratio } \\
\hline & $\mathbf{n}$ & $95 \% \mathrm{Cl}$ & Estimate & $95 \% \mathrm{Cl}$ & P value ** \\
\hline \multicolumn{6}{|c|}{ Resection extent } \\
\hline $\mathrm{GT}^{*}$ & 27 & $11.9 \pm 4.4$ & reference & & \\
\hline Subtotal & 26 & $9.9 \pm 9.2$ & 1.08 & $0.59-1.97$ & $=0.792$ \\
\hline Biopsy & 10 & $9.6 \pm 1.1$ & 0.88 & $0.38-2.02$ & $=0.768$ \\
\hline
\end{tabular}


Citation: Larson EW, Peterson HE, Lamoreaux WT, MacKay AR, Fairbanks RK, et al. (2014) Case Series: Gamma Knife as Salvage Therapy for

\begin{tabular}{|c|c|c|c|c|c|}
\hline \multicolumn{6}{|c|}{ Age at diagnosis } \\
\hline$<50^{*}$ & 19 & $12.3 \pm 11.7$ & reference & & \\
\hline$\geq 50$ & 44 & $9.6 \pm 2.4$ & 1.44 & $0.81-2.54$ & $=0.221$ \\
\hline \multicolumn{6}{|l|}{ KPS } \\
\hline 60 & 3 & $3.0 \pm 3.2$ & 8.55 & $1.08-66.67$ & $=0.021$ \\
\hline 70 & 16 & $5.7 \pm 2.5$ & 1.21 & $0.52-2.81$ & $=0.699$ \\
\hline $80^{*}$ & 17 & $9.3 \pm 2.1$ & reference & & \\
\hline 90 & 12 & $11.9 \pm 3.7$ & 0.65 & $0.28-1.50$ & $=0.308$ \\
\hline 100 & 12 & $17.9 \pm 5.5$ & 0.35 & $0.12-0.99$ & $=0.034$ \\
\hline Unknown & 3 & insufficient data & 0.74 & $0.52-2.81$ & $=0.699$ \\
\hline \multicolumn{6}{|c|}{ GK dose (Gy) } \\
\hline$<14$ & 14 & $9.6 \pm 12.8$ & 0.98 & $0.48-2.02$ & $=0.966$ \\
\hline $14-15$ & 15 & $7.9 \pm 3.8$ & 1.41 & $0.68-2.92$ & $=0.314$ \\
\hline $16^{*}$ & 29 & $11.9 \pm 2.8$ & reference & & \\
\hline$>16$ & 5 & $4.7 \pm 4.5$ & 0.78 & $0.24-2.51$ & $=0.638$ \\
\hline \multicolumn{6}{|c|}{ Tumor volume (cc) } \\
\hline$<15^{*}$ & 26 & $13.9 \pm 4.2$ & reference & & \\
\hline$\geq 15$ & 28 & $7.2 \pm 2.7$ & 1.97 & $1.06-3.66$ & $=0.019$ \\
\hline Unknown & 9 & $9.1 \pm 4.0$ & 1.61 & $0.61-4.35$ & $=0.252$ \\
\hline
\end{tabular}

Table 3: Univariate median survival estimates (months) and hazard ratios, ${ }^{*}$ Reference group against which other groups' survival experience are compared. ${ }^{* *} \mathrm{P}$ value for log-rank testing the null hypothesis that the groups' survival experience is same as reference group, GT: gross total resection, KPS: Karnofsky Performance Status, GK: Gamma Knife

\begin{tabular}{|c|c|c|c|}
\hline & \multicolumn{3}{|c|}{ Hazard Ratio } \\
\hline & Estimate & $95 \% \mathrm{Cl}$ & $P$ value ${ }^{* *}$ \\
\hline \multicolumn{4}{|c|}{ Resection extent } \\
\hline $\mathrm{GT}^{*}$ & \multicolumn{3}{|l|}{ reference } \\
\hline Subtotal & 0.97 & $0.44-2.15$ & 0.941 \\
\hline Biopsy & 0.41 & $0.14-1.18$ & 0.098 \\
\hline \multicolumn{4}{|c|}{ Age at diagnosis } \\
\hline$<50^{*}$ & \multicolumn{3}{|l|}{ reference } \\
\hline$\geq 50$ & 1.38 & $0.67-2.85$ & 0.383 \\
\hline \multicolumn{4}{|l|}{ KPS } \\
\hline 60 & 8.09 & $3.69-17.78$ & $<0.001$ \\
\hline 70 & 1.47 & $1.35-1.61$ & $<0.001$ \\
\hline $80^{*}$ & reference & & \\
\hline 90 & 0.53 & $0.19-1.47$ & 0.230 \\
\hline 100 & 0.22 & $0.15-0.33$ & $<0.001$ \\
\hline
\end{tabular}

\begin{tabular}{|c|c|c|c|}
\hline Unknown & 1.10 & $0.31-3.92$ & 0.880 \\
\hline \multicolumn{4}{|c|}{ GK dose (Gy) } \\
\hline$<14$ & 0.71 & $0.25-2.07$ & 0.535 \\
\hline $14-15$ & 1.15 & $0.41-3.18$ & 0.793 \\
\hline $16^{*}$ & reference & & \\
\hline$>16$ & 0.66 & $0.14-3.16$ & 0.602 \\
\hline \multicolumn{4}{|c|}{ Tumor volume (cc) } \\
\hline$<15^{*}$ & \multicolumn{3}{|l|}{ reference } \\
\hline$\geq 15$ & 1.95 & $0.81-4.71$ & 0.138 \\
\hline Unknown & 3.68 & $1.08-12.58$ & 0.038 \\
\hline
\end{tabular}

Table 4: Multivariate hazard ratios, confidence intervals, and $\mathrm{P}$ values, ${ }^{*}$ Reference group against which other groups' survival experience are compared. ${ }^{* *} \mathrm{P}$ value for test if groups' survival experience is same as reference group. GT: gross total resection, KPS: Karnofsky Performance Status, GK: Gamma Knife 
The multivariate analysis hazard ratio estimates and confidence intervals are included in Table 4 . The multivariate analysis utilized the same reference groups as the univariate analyses against which the other groups' hazard ratios were tested. The multivariate analysis did not find statistically significant differences in the resection extent, age, or gamma knife dose groups. Regarding KPS groups, the multivariate analysis indicated the KPS groups of 60,70 , and 100 all differed from the reference group of 80 (P-values $<0.001$ ).

Interestingly, the multivariate analysis indicated that tumor volume was not statistically significant $(\mathrm{p}=0.138)$.

\section{Discussion}

Almost all GBM patients will suffer a recurrence of their tumor and is incurable despite all available interventions [2]. In an effort to curb this dismal prognosis, it is imperative to study methods to treat this recurrence. This study aims to retrospectively analyze whether GKRS is effective as a salvage treatment option. Moreover, it is important to identify which patients are most likely to benefit from this treatment. To that end, overall survival outcomes from this study are compared to the updated RTOG recursive partitioning analysis (RTOG-RPA) described by Li et al. in 2010 which focused specifically on GBM histopathology [13]. The Li study identifies three RTOG-RPA classes: III, IV, and V with overall survival rates of 17.1, 11.2, and 7.5 months from initial diagnosis, respectively. Significant predictors of prognosis that they found are KPS, age, extent of resection, and neurologic function $[13,37]$. In the present study, RTOG-RPA Class was determined in $95 \%$ of patients with the greatest survival advantage appreciated by patients in Class IV: 20.2 months (Table 2) (Figure 4). In prior studies recently reviewed [38], median overall survival for all patients treated with salvage GKRS was from 16.7 to 33.2 months [15,16,18,30-35].

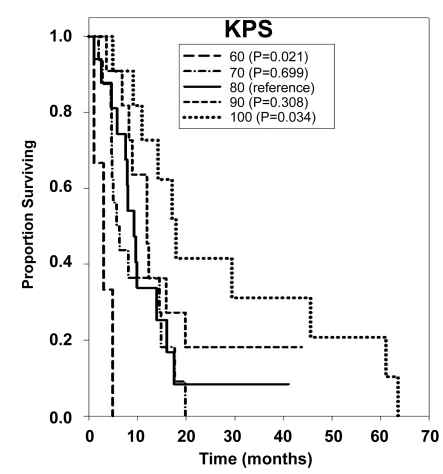

Figure 4: Overall survival curves based on Karnofsky Performance Status (KPS)

It is also informative to analyze which patient characteristics predict longer survival following salvage therapy. In this study, the most significant predictor of survival post-GKRS salvage was KPS score. This is based on the results from multivariate analysis and is consistent with other reports on GKRS salvage for rGBM. Elliott, et al. found improved outcomes for KPS $\geq 90$ in their multivariate analysis [15]. The present study found no difference between KPS of 80 and 90 on multivariate analysis. Also, while patients with KPS scores of 60 and 70 faired significantly worse following GKRS salvage, comparing their survival rates to those in patients who do not receive salvage therapy may be worthwhile.

Evidence shows that patient age is a reliable predictor of overall survival following the initial diagnosis of GBM $[10,11,19,30,39]$, but this study and others appear to suggest that it is not associated with survival differences following GKRS salvage (Tables 3 and 4) $[15,18]$. These data, along with the aforementioned RTOG-RPA comparison, suggest that older patients with favorable KPS scores are likely to appreciate similar post-salvage survival advantages as younger patients. Therefore, they ought to be considered as candidates. Likewise, this study did not find a post-salvage survival difference for patients who initially had gross total resection, subtotal resection, or biopsy as part of their adjuvant therapy following diagnosis of GBM (Tables 3 and 4) (Figure 3). This lack of statistical significance may be explained by the relatively small number of patients in each subgroup. An opposing view may be that regardless of initial extent of resection, it is important to continue to treat all visibly recurrent tumor tissue with radiosurgery as early as possible following detection on surveillance MRI. That said, salvage surgical resection, with or without GKRS, has been demonstrated to show a survival advantage for those patients who are eligible $[18,25,40,41]$.

Multiple studies on salvage rGBM suggest that patients with smaller volume tumors seem to experience a greater survival advantage $[15,16,18,38]$. In the present study, multivariate analysis does not show significant survival difference when comparing tumors $<15 \mathrm{cc}$ and those $\geq 15 \mathrm{cc}$ (Table 4 ). This suggests that those patients suffering from a larger volume recurrence may still benefit from GKRS salvage.

This study is limited by its retrospective nature, without a control group. It may represent a selection bias in that those patients who are deemed eligible for Gamma Knife treatment could be in an advantageous position when it comes to rGBM survival. Also, some patients are deemed unfit for repeated resection, either by clinical assessment by the surgeon of the patient's ability to survive such an invasive procedure, or by patient preference. Until a randomized, controlled clinical trial is performed for GKRS for rGBM patients, this evidence has a limited scope for informing clinical practice $[38,42]$. However, the data from this study suggests a survival benefit independently of age, KPS score, and extent of resection including biopsy only.

Each rGBM patient and their family need to be counseled by the healthcare team to determine which surgical and medical options are available. An individually tailored, multimodal treatment plan based on tumor location and the patient's functional capacity should be offered in order to meet the individual's goals [43].

\section{Conclusions}

GKRS salvage therapy for selected patients with rGBM showed overall median survival of 20.2 months and post-treatment survival of 9 months. When considering their RTOG-RPA classifications, these patients experienced longer survival than predicted. These results were independent of the size of the tumor and treatment dose. Those with better KPS scores tended to have longer post-GKRS survival. 


\section{Acknowledgments}

We would like to thank the research support staff of Cancer Care Northwest as well as Eric Reynolds and Jill Adams of Gamma Knife Spokane.

\section{References}

1. Schwartzbaum JA, Fisher JL, Aldape KD, Wrensch M (2006) Epidemiology and molecular pathology of glioma. Nat Clin Pract Neurol 2: 494-503.

2. Goodenberger ML, Jenkins RB (2012) Genetics of adult glioma. Cancer Genet 205: 613-621

3. Krex D, Klink B, Hartmann C, von Deimling A, Pietsch T, et al. (2007) Long-term survival with glioblastoma multiforme. Brain 130: 2596-2606.

4. Souhami L, Seiferheld W, Brachman D, Podgorsak EB, Werner-Wasik M, et al. (2004) Randomized comparison of stereotactic radiosurgery followed by conventional radiotherapy with carmustine to conventional radiotherapy with carmustine for patients with glioblastoma multiforme: report of Radiation Therapy Oncology Group 93-05 protocol. International journal of radiation oncology, biology, physics 60: 853-60.

5. Stupp R, Hegi ME, Mason WP, van den Bent MJ, Taphoorn MJ, et al. (2009) Effects of radiotherapy with concomitant and adjuvant temozolomide versus radiotherapy alone on survival in glioblastoma in a randomised phase III study: 5-year analysis of the EORTC-NCIC trial. Lancet Oncol 10: 459-466.

6. Barker FG 2nd, Prados MD, Chang SM, Gutin PH, Lamborn KR, et al. (1996) Radiation response and survival time in patients with glioblastoma multiforme. J Neurosurg 84: 442-448.

7. Butowski N, Prados MD, Lamborn KR, Larson DA, Sneed PK, et al. (2005) A phase II study of concurrent temozolomide and cis-retinoic acid with radiation for adult patients with newly diagnosed supratentorial glioblastoma. International journal of radiation oncology, biology, physics 61: 1454-1459.

8. Hou LC, Veeravagu A, Hsu AR, Tse VC (2006) Recurrent glioblastoma multiforme: a review of natural history and management options. Neurosurg Focus 20: E5.

9. Biswas T, Okunieff P, Schell MC, Smudzin T, Pilcher WH, et al. (2009) Stereotactic radiosurgery for glioblastoma: retrospective analysis. Radiat Oncol 4: 11.

10. Curran WJ, Jr., Scott CB, Horton J, Nelson JS, Weinstein AS, et al. (1993) Recursive partitioning analysis of prognostic factors in three Radiation Therapy Oncology Group malignant glioma trials. Journal of the National Cancer Institute 85: 704-710.

11. Li J, Wang M, Won M, Shaw EG, Coughlin C, et al. (2011) Validation and simplification of the Radiation Therapy Oncology Group recursive partitioning analysis classification for glioblastoma. Int J Radiat Oncol Biol Phys 81: 623-630.

12. Scott CB, Scarantino C, Urtasun R, Movsas B, Jones CU, et al. (1998) Validation and predictive power of Radiation Therapy Oncology Group (RTOG) recursive partitioning analysis classes for malignant glioma patients: a report using RTOG 90-06. International journal of radiation oncology, biology, physics 40: 51-55.

13. Lai A, Tran A, Nghiemphu PL, Pope WB, Solis OE, et al. (2011) Phase II study of bevacizumab plus temozolomide during and after radiation therapy for patients with newly diagnosed glioblastoma multiforme. Journal of clinical oncology : official journal of the American Society of Clinical Oncology 29: 142-148.

14. Barker FG 2nd, Chang SM, Larson DA, Sneed PK, Wara WM, et al. (2001) Age and radiation response in glioblastoma multiforme. Neurosurgery 49: 1288-1297.

15. Elliott RE, Parker EC, Rush SC, Kalhorn SP, Moshel YA, et al. (2011) Efficacy of gamma knife radiosurgery for small-volume recurrent malignant gliomas after initial radical resection. World Neurosurg 76: 128-140.
16. Park KJ, Kano H, Iyer A, Liu X, Niranjan A, et al. (2012) Salvage gamma knife stereotactic radiosurgery followed by bevacizumab for recurrent glioblastoma multiforme: a case-control study. J Neurooncol 107: 323-333.

17. Gorlia T, van den Bent MJ, Hegi ME, Mirimanoff RO, Weller M, et al. (2008) Nomograms for predicting survival of patients with newly diagnosed glioblastoma: prognostic factor analysis of EORTC and NCIC trial 26981-22981/CE.3. The lancet oncology 9: 29-38.

18. Skeie BS, Enger PØ, Brøgger J, Ganz JC, Thorsen F, et al. (2012) $\hat{\mathrm{I}}^{3}$ knife surgery versus reoperation for recurrent glioblastoma multiforme. World Neurosurg 78: 658-669.

19. Thumma SR, Fairbanks RK, Lamoreaux WT, Mackay AR, Demakas JJ, et al. (2012) Effect of pretreatment clinical factors on overall survival in glioblastoma multiforme: a Surveillance Epidemiology and End Results (SEER) population analysis. World journal of surgical oncology 10: 75 .

20. Silbergeld DL, Chicoine MR (1997) Isolation and characterization of human malignant glioma cells from histologically normal brain. J Neurosurg 86: 525-531.

21. Cecchi M, Vaiani M, Ceroti M, Banfi R (2013) A retrospective observational analysis to evaluate the off-label use of bevacizumab alone or with irinotecan in recurrent glioblastoma. Int J Clin Pharm 35: 483-487.

22. Kano H, Kondziolka D, Lobato-Polo J, Zorro O, Flickinger JC, et al. (2010) T1/T2 matching to differentiate tumor growth from radiation effects after stereotactic radiosurgery. Neurosurgery 66: 486-491.

23. Khasraw M, Simeonovic M, Grommes C (2012) Bevacizumab for the treatment of high-grade glioma. Expert Opin Biol Ther 12: 1101-1111.

24. Larson EW, Peterson HE, Fairbanks RK, Lamoreaux WT, Mackay AR, et al. (2013) Long-Term Survival and Improved Quality of Life following Multiple Repeat Gamma Knife Radiosurgeries for Recurrent Glioblastoma Multiforme: A Case Report and Review of the Literature. Case reports in oncological medicine 2013: 431857.

25. Chaichana KL, Zadnik P, Weingart JD, Olivi A, Gallia GL, et al. (2013) Multiple resections for patients with glioblastoma: prolonging survival. J Neurosurg 118: 812-820.

26. De Bonis P, Anile C, Pompucci A, Fiorentino A, Balducci M, et al. (2013) The influence of surgery on recurrence pattern of glioblastoma. Clin Neurol Neurosurg 115: 37-43.

27. Wong CS, Van der Kogel AJ (2004) Mechanisms of radiation injury to the central nervous system: implications for neuroprotection. Mol Interv 4: 273-284.

28. Monaco EA 3rd, Niranjan A, Kano H, Flickinger JC, Kondziolka D, et al. (2012) Management of adverse radiation effects after radiosurgery. Prog Neurol Surg 25: 210-220.

29. Patel M, Siddiqui F, Jin JY, Mikkelsen T, Rosenblum M, et al. (2009) Salvage reirradiation for recurrent glioblastoma with radiosurgery: radiographic response and improved survival. J Neurooncol 92: 185-191.

30. Hsieh PC, Chandler JP, Bhangoo S, Panagiotopoulos K, Kalapurakal JA, et al. (2005) Adjuvant gamma knife stereotactic radiosurgery at the time of tumor progression potentially improves survival for patients with glioblastoma multiforme. Neurosurgery 57: 684-692; discussion 684-92.

31. Kida Y, Yoshimoto M, Hasegawa T (2009) Radiosurgery for intracranial gliomas. Prog Neurol Surg 22: 122-128.

32. Koga T, Maruyama K, Tanaka M, Ino Y, Saito N, et al. (2012) Extended field stereotactic radiosurgery for recurrent glioblastoma. Cancer 118: 4193-4200.

33. Kohshi K, Yamamoto H, Nakahara A, Katoh T, Takagi M (2007) Fractionated stereotactic radiotherapy using gamma unit after hyperbaric oxygenation on recurrent high-grade gliomas. Journal of neuro-oncology 82: $297-303$.

34. Kong DS, Lee JI, Park K, Kim JH, Lim DH, et al. (2008) Efficacy of stereotactic radiosurgery as a salvage treatment for recurrent malignant gliomas. Cancer 112: 2046-2051. 
Citation: Larson EW, Peterson HE, Lamoreaux WT, MacKay AR, Fairbanks RK, et al. (2014) Case Series: Gamma Knife as Salvage Therapy for Recurrent Glioblastoma Multiforme. Brain Disord Ther 3: 143. doi:10.4172/2168-975X.1000143

Page 7 of 7

35. Pouratian N, Crowley RW, Sherman JH, Jagannathan J, Sheehan JP (2009) Gamma Knife radiosurgery after radiation therapy as an adjunctive treatment for glioblastoma. J Neurooncol 94: 409-418.

36. Armitage P, Berry G (1994) Statistical methods in medical research. (3rd edn), Blackwell Scientific Publications, Oxford ; Boston.

37. Sanai N, Polley MY, McDermott MW, Parsa AT, Berger MS (2011) An extent of resection threshold for newly diagnosed glioblastomas. J Neurosurg 115: 3-8.

38. Larson EW, Peterson HE, Lamoreaux WT, MacKay AR, Fairbanks RK, et al. (2014) Clinical outcomes following salvage Gamma Knife radiosurgery for recurrent glioblastoma. World J Clin Oncol 5: 142-148.

39. Davis FG, Freels S, Grutsch J, Barlas S, Brem S (1998) Survival rates in patients with primary malignant brain tumors stratified by patient age and tumor histological type: an analysis based on Surveillance,
Epidemiology, and End Results (SEER) data, 1973-1991. Journal of neurosurgery 88: 1-10.

40. Barker FG 2nd, Chang SM, Gutin PH, Malec MK, McDermott MW, et al. (1998) Survival and functional status after resection of recurrent glioblastoma multiforme. Neurosurgery 42: 709-720.

41. Keles GE, Anderson B, Berger MS (1999) The effect of extent of resection on time to tumor progression and survival in patients with glioblastoma multiforme of the cerebral hemisphere. Surg Neurol 52: 371-379.

42. Crowley RW, Pouratian N, Sheehan JP (2006) Gamma knife surgery for glioblastoma multiforme. Neurosurg Focus 20: E17.

43. Thumma SR, Elaimy AL, Daines N, Mackay AR, Lamoreaux WT, et al. (2012) Long-term survival after gamma knife radiosurgery in a case of recurrent glioblastoma multiforme: a case report and review of the literature. Case Rep Med 2012: 545492. 